\title{
СРАВИТЕЛЬНЫЙ АНАЛИЗ ЗАКОНОДАТЕЛЬСТВА ГОСУДАРСТВ-ЧЛЕНОВ ЕАЭС В ОБЛАСТИ ОРГАНИЧЕСКОГО СЕЛЬСКОГО ХОЗЯЙСТВА
}

В настоящее время, наряду с традиционным интенсивным аграрным производством, получает развитие органическое сельское хозяйство, целью которого является получение экологически чистых продуктов растениеводства и животноводства. В странах-членах Евразийского экономического союза процесс формирования законодательства об органическом сельском хозяйстве только начался. Исключение составляет Армения, где закон «Об органическом сельском хозяйстве» был принят в 2008 году. В Республике Казахстан Закон «О производстве органической продукции» существует с 2015 года. В Республике Беларусь и в Российской Федерации соответствующие законы приняты, но еще не вступили в действие. В Киргизской Республике существует законопроект «Об органическом сельскохозяйственном производстве». Сельское хозяйство признано приоритетным направлением в развитии сотрудничества стран-членов ЕАЭС. В перспективе - принятие Правил обращения органической продукции Союза. В этой связи рассмотрение и сравнительный анализ национального законодательства представляется актуальным. Поскольку в большинстве стран-членах ЕАЭС соответствующие законы приняты совсем недавно и еще не подвергались комплексному анализу, можно говорить и о новизне предмета исследования.

В процессе исследования выявлены несовпадения в правовых подходах, связанные с неодинаковой трактовкой национальными законодателями понятия органической продукции, стадий обращения (производство, переработка, хранение, транспортировка, реализация). Основу правового режима составляют требования, предъявляемые к производству экопродукции. Их соблюдение позволяет в последующем времени претендовать на соответствующий бренд (маркировку)

При всей схожести набора функций публичного управления, авторы указывают на ряд различий, присущих как системам функций, так и правовой регламентации их содержания

В этой связи в статье даются рекомендации, направленные на унификацию и гармонизацию правового регулирования производства экопродукции в странах ЕАЭС.

Ключевые слова: органическое сельское хозяйство, ЕАЭС, правовое регулирование.

E. Navasardova, A. Zakharin

\section{COMPARATIVE ANALYSIS OF THE LEGISLATION OF THE EAEU MEMBER STATES IN THE FIELD OF ORGANIC AGRICULTURE}

At present, organic agriculture is developing along with the traditional intensive agricultural production. Its purpose is to obtain environmentally friendly products of crop and livestock. In the member states of the Eurasian Economic Union, the process of forming legislation on organic agriculture has just begun. The exception is Armenia, where the law "On organic agriculture" was adopted in 2008. In the Republic of Kazakhstan, the Law "On organic production" has been in force since 2015. The Republic of Belarus and the Russian Federation have adopted relevant laws, but they have not yet entered into force. There is a draft law on organic agricultural production in the Kyrgyz Republic. Agriculture is recognized as a priority in the development of cooperation of the EAEU member states. There will be the adoption of Rules for the circulation of organic products of the Union in the future. In this regard, consideration and comparative analysis of national legislation is relevant Since most of the EAEU member States have recently adopted relevant laws and have not yet been subjected to a

Органическое земледелие, а точнее органическое сельскохозяйственное производство имеет давнюю историю. Суть его заключается в основ- comprehensive analysis, we can also talk about the novelty of the subject of the study.

The study has revealed discrepancies in legal approaches associated with different interpretations by national legislators of the concept of organic products, the stages of circulation (production, processing, storage, transportation, and sale). The basis of the legal regime is the requirements for the production of eco-products. Their observance allows in the subsequent time to apply for the corresponding brand (marking).

Despite the similarity of the set of functions of public administration, the authors point to a number of differences inherent in both systems of functions and legal regulation of their content.

In this regard, the article provides recommendations aimed at unification and harmonization of legal regulation of production of eco-products in the EAEU countries.

Key words: organic agriculture, Eurasian Economic Union, legal regulation.

ных принципах аграрного производства - не использование химических веществ, иных неприродного происхождения компонентов, особые 
методы обработки почвы. Причем это касается не только растениеводства, но и животноводства. Возрождение экологического сельского хозяйства в настоящее время связано с рядом факторов. Считается, что органическое земледелие, в частности, сокращает затраты (имеются в виду ядохимикаты, химические удобрения) и дает стабильно высокие урожаи. Кроме того, предполагается, что продукты органического сельского хозяйства безопасны для человека. Этот вид аграрного производства не наносит вреда окружающей среде, а напротив, приводит к гармонии в системе «общество-природа». Известно, что интенсивное сельскохозяйственное производство ведет к загрязнению земель, подземных вод, возникновению эрозии почв, в произведенной продукции остаются вредные для здоровья человека химические соединения, в мясе и молоке, помимо всего прочего, обнаруживаются антибиотики, используемые для профилактики и лечения заболеваний сельскохозяйственных животных и т.д.

Страны-участницы Евразийского экономического союза планируют создать единый рынок органической продукции, для чего, собственно, и нужна гармонизация законодательства.

В начале 1990-х годов государствам постсоветского пространства было не до органического земледелия. Зато в эти годы оно начало развиваться в мире как отражение потребностей в экологически чистой продукции. В настоящее время органическое аграрное производство в мире ведется в 178 странах [1]. На уровне ЕС принят ряд нормативных документов, регламентирующих производство органической продукции. В их числе Директива ЕС по органическому производству и маркировке органических продуктов № 834/2007 и Директива ЕС № 889/2008, недавно принят новый регламент ЕС по органическому сельскому хозяйству 848/2018, который вступит в действие 1 января 2021 года.

Страны-члены ЕАЭС в настоящее время проводят работу по подготовке к принятию правил обращения органической продукции. Поэтому изучение уже имеющихся законодательных актов, регулирующих производство органической продукции актуально, а поскольку в некоторых странах-участницах соответствующие законы приняты совсем недавно и еще не подвергались комплексному анализу, можно говорить и о новизне предмета исследования.

Нормативная база на постсоветском пространстве, регулирующая органическое сельское хозяйство, начала формироваться в рамках СНГ. Она представлена Модельным законом об экологическом агропроизводстве от 18.04.2014 (далее Модельный закон СНГ.). Это на сегодняшний день, наиболее детализированный, с точки зрения правового закрепления требований, нормативный акт

Что касается собственно стран-членов ЕАЭС, то пионером в законотворчестве выступила Республика Армения, где в 2008 году был принят Закон «Об органическом сельском хозяйстве».
В 2015 году в Республике Казахстан принят Закон «О производстве органической продукции». В 2018 год процесс разработки аналогичных законов завершили Республика Беларусь (Закон РБ от 9.11.2018 № 144-3 «О производстве и обращении органической продукциим) и Российская Федерация (ФЗ от 03.08.2018 N 280-Ф3 «Об органической продукции и о внесении изменений в отдельные законодательные акты Российской Федерации»), дело за Киргизской Республикой, где пока существует только проект закона «Об органическом сельскохозяйственном производстве в Кыргызской Республике». В Беларуси основные положения Закона вступают в силу через год после его официального опубликования, и в России - с 1 января 2020 года, т.е. практически одновременно.

Каково же содержание исследуемых законов? Что общего и различного, имеющего принципиальное значение есть в них?

Начнем с понятийного аппарата. Так, в Законе Белоруссии под органической понимается продукция как растительного, так и животного, а также микробиологического происхождения, которые предназначены для употребления в пищу человеком либо могут использоваться как корм для животных, а также как продовольственное сырье, необходимое для производства пищевых продуктов. К органической продукции отнесены семена, которые получены в результате производства этой продукции. Отдельно регламентируются требования, предьявляемые к пчеловодству.

Российская формулировка более лаконична. Она определяет органическую продукцию как экологически чистую сельскохозяйственную продукцию, сырье и продовольствие, производство которой соответствует требованиям законодательства.

Отличительная особенность Закона Республики Казахстан - прямое указание на распространение его действия в отношении продукции аквакультуры (рыбоводства) и продукции из дикорастущих растений.

Следует отметить, что в стадии обращения в ряде стран включаются не только собственно производство, но также хранение, переработка транспортировка и реализация, причем набор элементов может быть разным.

Важными элементами механизма производства экологически чистой продукции и доведения ее до потребителя является регламентация не только производства, но также хранения, транспортировки, маркировки и реализации. Российское законодательство все указанные элементы включает в понятие «производство», проект закона Киргизии - производству, хранению и переработки, Закон Республики Казахстан говорит о производстве и обороте органической продукции.

Основу правового режима составляют требования, предъявляемые к производству экопродукции. Их соблюдение позволяет в последующем времени претендовать на соответствующий бренд (маркировку) 
Российское законодательство формулирует их следующим образом:

- Производство органической продукции должно быть обособлено от традиционного сельскохозяйственного производства. В то же время разрешается одному товаропроизводителю пользоваться и экологически чистыми технологиями и традиционными. Суть этого требования сводится к недопущению возможности, например, перекрестного опыления, загрязнения ядохимикатами подземных вод, иным негативным воздействиям, другими словами, недопущение контакта органической и неорганической продукции на всех стадиях обращения.

- Запрещение применения химических средств борьбы с вредителями и болезнями растений антибиотиков, стимуляторов роста и откорма животных, а также гормональных препаратов. При этом российский законодатель допускает использование применения препаратов, разрешенных отечественными, межгосударственными и международными стандартами, установленными в отношении производства органической продукции. Например, для защиты растений допускается применение гидроксида кальция, гидрокарбоната натрия, других соединений как базовых и имеющих растительное или животное происхождение.

- Запрещение применения продуктов, подвергшихся генной модификации, а также трансгенных организмов, иных продуктов, полученных посредством клонирования и методов генной инженерии

- Запрещение выращивание сельскохозяйственных растений без использования почвы.

- Не применение ионизирующего излучения.

- Использование средств биологического происхождения для борьбы с вредителями и болезнями растений и животных. Закон также предписывает сельхозпроизводителям осуществлять меры, предупреждающие потери, которые наносятся вредными организмами растениям или продукции растительного происхождения, основанные на защите естественных врагов вредителей растений, иные меры, связанные с выбором способов обработки почв, видов и сортов выращиваемых растений, иных методов аграрного производства (севообороты, обработка продукции).

- Осуществление выбора пород и видов сельскохозяйственных животных, при учете их способностей к адаптации, устойчивости к болезням создание иных условий, направленных на ветеринарное и санитарно-гигиеническое благополучие при содержании животных.

- Использование пищевых добавок, иных средств, которые допускаются российскими, межгосударственными и международными стандартами при производстве органической продукции.

- Применение биологических микроорганизмов, которые традиционно используется при переработке пищевой продукции, использование мер защиты продукции животного происхождения от микробиологической порчи, основанных на взаимодействии микроорганизмов в естественной природной среде;
- Запрещение смешивания продукции органического производства с продукцией, которая не относится к таковой, при организации хранении и транспортировке органической продукции;

Запрещение использования упаковки, тары, которые способны привести к загрязнению органической продукции и окружающей среды, включая использование поливинилхлорида для упаковки, потребительской и транспортной тары.

Общий контекст требований, содержащихся в российском законе, поддержан и в законе Республики Беларусь, однако, там есть и особенности, например, касающиеся органического производства продукции пчеловодства. Отдельно прописаны требования относительно использования семян, они также должны быть получены в результате производства органической продукции. Особо следует отметить нормы белорусского закона, касающееся запрета на использование земельных участков, водных объектов и (или) их частей, подвергшихся загрязнению отходами, химическими и радиоактивными веществами. Дело в том, что подавляющее большинство земель и водных объектов загрязнены в большей или меньшей степени. Земли загрязнены вследствие использования химических удобрений, пестицидов и гербицидов, но, в принципе, реабилитация таких почв возможна. Гораздо сложнее обстоят дела с водными объектами. Поверхностные водные объекты загрязняются одновременно многими водопользователями, сбрасывающими в них сточные воды, иные отходы производства и потребления. Подземные воды загрязняются и посредством использования тех же химических веществ, применяемых в сельском хозяйстве, и в результате деятельности животноводческого комплекса, и как следствие работы иных промышленных объектов. Их очистка крайне затруднена, если вообще возможна.

Закон Республики Казахстан также говорит о необходимости сохранения и воспроизводства плодородия почв, правда, не вполне понятна норма, призывающая к минимизации использования невозобновляемых природных ресурсов. Здесь, видимо, речь идет о водных ресурсах.

При этом ни один из исследуемых законов не упоминает качество иных природных объектов, загрязнение которых может отрицательно сказаться и на состоянии почв, и на состоянии водных объектов, например, загрязнения атмосферного воздуха.

Отдельный блок норм посвящен публичному управлению в области производства и обращения органической продукции.

Законы некоторых стран-членов ЕАЭС закрепляют нормы, касающееся системы органов публичного управления в указанной сфере и, что важно, обозначают уполномоченный орган.

Функции, выполняемые органами публичной власти в сфере органического сельского хозяйства, можно подразделить на фрунццю стандартизации, информационную, контрольную (надзорную) функции. Методы управления можно в 
виде запретов и ограничений, а также мер по стимулированию этого вида аграрного производства.

Функция стандартизации заключается в том, что помимо признания странами-членами ЕАЭС международных стандартов, в них разрабатываются собственные требования по производству органической продукции. В РФ, например, действует несколько таких стандартов. Кроме того, вводится добровольная сертификация, приводимая, в частности в РФ согласно требованиям Ф3 от 27.12.2002 N184-Ф3 (ред. от 29.07.2017) «О техническом регулировании». Сертификация подтверждает соответствие производства органической продукции национальным, межгосударственным и международным стандартам в исследуемой сфере. При этом по российскому закону добровольная сертификация продукции не заменяет обязательное подтверждение соответствия органических продуктов в случаях, предусмотренных актами, составляющими право Евразийского экономического союза, и законодательством Российской Федерации. То есть, отечественное законодательство предполагает, по сути, необходимость обязательного прохождения процедуры подтверждения соответствия

Почти аналогичные требования о сертификации изложены и в Законе Республики Беларусь. Там, согласно понятийному аппарату, заведомо производителем органической продукции признается лицо, имеющее сертификат соответствия, который выдается Национальной системой подтверждения соответствия Республики Беларусь. Данный документ является основанием для его включения в реестр производителей органической продукции. Иными словами, наличие сертификата является основанием для включения товаропроизводителя в Реестр. Те же нормы прописаны и в Законе Республики Казахстан, с тем лишь исключением, что в отличие от России и Беларуси цитируемый Закон обязывает органы сертификации направлять информацию о ее результатах в местные исполнительные органы областей, городов республиканского значения и столицы.

Полагаем, что сертификация соответствия производства органической продукции должна быть обязательной и наличие сертификата соответствия должно явиться основанием для включения сведений о ней и ее производителе в реестр. Правда, возникает вопрос, что должно сертифицироваться?

По закону Республики Беларусь сертификат выдается в отношении органической продукции и процессов ее производства. В отечественном законодательстве речь идет о сертификации процесса производства. В законе Республики Казахстан речь также идет о сертификации процесса производства. Полагаем, что сертифицировать следует как процесс производства, так и произведенную продукцию, поскольку, как уже отмечалось, на качество продукции влияют не только технологические процессы, которые могут полностью соответствовать предъявляемым требованиям, но и качество почвы, загрязненность водных объектов (подземных и поверхностных), качество атмосферных осадков. При этом, как представляется, должны также сертифицироваться почвы, на которых это производство ведется.

Информационная функция реализуется посредством включения товаропроизводителей и их продукцию в реестры.

Наиболее подробно процесс ведения реестра (отечественным законом он признан государственным). Целью ведения этого документа, как указано в российском законе, является безвозмездное информирование потребителей о производителях органической продукции и видах производимой ими продукции и является федеральным информационным ресурсом. Из текста статьи, регулирующей порядок ведения этого документа, невозможно определить его правовое значение. Ответ на этот вопрос обнаруживается в понятийном аппарате, где сказано, что производителями органической продукции признаются лица, которые (далее перечисляются все стадии осуществления производства и дальнейшего оборота этой продукции), включены в единый государственный реестр производителей органической продукции. Судя по всему, с момента внесения сведений в единый государственный реестр начинается и отсчет времени, называемый переходным периодом, хотя прямо об этом в Законе не говорится.

Характеристика переходного периода от традиционного ведения аграрного производства к органическому заслуживает особого внимания, поскольку именно в регулировании этого вопроса имеются серьезные разночтения в законодательных актах стран-членов ЕАЭС. Так, согласно анализу, проведенному отечественным Союзом органического земледелия, в России протяженность этого периода в растениеводстве для пахотных угодий, пастбищ или многолетних кормовых культур составляет не менее двух лет до начала использования в качестве органических кормов, для многолетних культур (кроме кормовых культур) не менее трех лет до получения первого урожая. В Республике Казахстан продолжительность перехода земельных участков от производства продукции, не относящейся к органической продукции, к производству органической продукции составляет: для посевных площадей - не менее одного года, предшествующего посеву; для пастбищ - не менее шести месяцев с начала переходного периода; для многолетних культур (кроме кормовых растений) - не менее одного года до сбора первого урожая органических продуктов [2].

Таким образом, производители органической продукции Республики Казахстан находятся в более выгодном положении чем российские.

С так называемым переходным периодом связана еще одна проблема. Дело в том, что еще до принятия российского Закона, уже велось производство органической продукции, ориентированное на европейское законодательство. Однако в Законе не делается исключение для таких производителей и наравне с теми, кто приступит к ведению этого вида аграрного производства сей- 
час или после вступления в силу отечественного Закона, придется проходить переходный период. Полагаем, что в Законе либо в подзаконных актах должно предусматриваться исключение в части переходного периода для лиц, уже занимающихся определенное время производством экологически чистой продукции. Кроме того, в Законе (законах стран-членов ЕАЭС) должна быть предусмотрена и возможность приостановки действия сертификата в случаях, связанных с, условно говоря, «чрезвычайными ситуациями» - эпидемиями, эпизоотиями и др. негативными факторами влияющими на процесс экопроизводства и требующими применение средств или технологий, не рекомендованных к использованию при производстве органической продукции.

Какие еще юридические последствия имеет получение сертификата? Согласно ст. 7 ФЗ от 03.08.2018 N80-Ф3 «Об органической продукции и о внесении изменений в отдельные законодательные акты Российской Федерации» после прохождения процедуры соответствия производства органической продукции ее производители имеют право разместить маркировку такой продукции которая и является ее отличительным признаком. При этом Закон не предусматривает единого обозначения продукции, оно может варьироваться по желанию производителей, единой должна быть графическая маркировка, которая может считываться, т.е. она должна содержать сведения о производителях экопродукции и видах производимой ими продукции, которые содержатся в едином государственном реестре производителей органической продукции. Закон Республики Беларусь устанавливает единое обозначение на экопродукции - «Органический продукт». Форму графического изображения в нашей стране определяет Минсельхоз РФ. Если маркировка нанесена, а продукция не подтверждена сертификатом, либо его действие аннулировано или прекращено, производитель несет ответственность в соответствии с законодательством РФ. В Законе не сказано, о какой ответственности идет речь. Видимо, имеется в виду ответственность за недобросовестную рекламу.

Следует обратить внимание на норму российского Закона, запрещающую экомаркировку на продукцию, произведенную в переходный период.

В отличие от отечественного Закона, закон Республики Казахстан напротив, разрешает реализовывать и маркировать продукцию как «переходную органическую продукцию». Проект Закона Киргизской Республики допускает маркировку продукции, произведенной в переходный период, как органической продукция при наличии соответствующего сертификата. Полагаем, что подобный подход дает преимущества производителям органической продукции и в этой части законодательство стран-членов ЕАЭС требует унификации

В системе функций публичного управления выделяется контрольная деятельность. Согласно Закону Республики Казахстан, государственный контроль в области производства органической продукции проводится в форме проверок и профилактического контроля, процедура и последствия которых подробно регламентированы Предпринимательским кодексом Республики Казахстан от 29 октября 2015 года №375-V (с последующими изменениями). В тексте Закона Республики Беларусь вопросы государственного надзора и контроля не упоминаются. Не упоминается указанная функция и в российском Законе. Это не означает, что производство органической продукции будет выведено из системы контроля и надзора. В нашей стране контрольно-надзорные функции должна исполнять Федеральная служба по ветеринарному и фитосанитарному надзору в соответствии с требованиями ФЗ от 26.12.2008 N294-Ф3 (ред. от 27.12.2018) «О защите прав юридических лиц и индивидуальных предпринимателей при осуществлении государственного контроля (надзора) и муниципального контроля».

Как уже отмечалось, одним из методов публичного управления в исследуемой сфере отношений, является метод стимулирования, обозначенный в анализируемых законах как государственная поддержка производителей органической продукции.

В белорусском Законе предусматривается возможность использования средств республиканского и местных бюджетов в рамках выполнения государственных программ в области производства и обращения органической продукции и других источников, не запрещенных законодательством, т.е. по крайней мере, говорится о государственных программах как источниках финансирования производства экопродукции.

Российский и казахский законы лишь указывают на возможность государственной поддержки, не называя ее формы. Правда, российский Закон отсылает нас к Ф3 от 29.12.2006 N264-Ф3 (ред. от 25.12.2018) «О развитии сельского хозяйства». Полагаем, что заинтересованность государства, если она есть, должна быть более конкретна. Было бы целесообразным закрепить в документах, регулирующих органическое сельское хозяйство, указание на принятие специальных государственных программ, где адресно и конкретизировано будут закреплены финансируемые мероприятия, связанные с развитием этого аграрного сектора. Кроме того, возможно законодательное закрепление возможности наделения субъектов аграрного производства, выразивших желание производить экопродукцию, бесплатно передавать им залежные земли. Это земли, неиспользуемые и в силу чего могут быть изъяты у их владельцев. Естественно, эти земли не должны быть загрязнены отходами либо химическими и радиоактивными веществами. И естественно, производители органической продукции должны пользоваться и иными формами государственной поддержки (финансовый лизинг, страхование и др.).

Проведенный сравнительный анализ законодательства показал, что государства-участники ЕАЭС вслед за большинством развитых стран, включились в процесс формирования законодательства в области развития органического сельского хозяйства. Вместе с тем, как было 
показано, некоторые положения национального законодательства нуждаются в унификации и гармонизации. Однако прежде всего необходимо принять единый нормативный правовой акт
ЕАЭС, который будет являться ориентиром для совершенствования национального аграрного законодательства.

\section{Литература}

1. Ежегодный консолидированный отчет IFOAM-2017. URL: https://ifoam.bio. (Дата обращения: 22.05.2019).

2. В Евразийском экономическом союзе вырабатывают правила обращения органической продукции URL: https:// soz.bio/v-evrazijskom-ekonomicheskom-soyuze-vyrabatyvayut-pravila-obrashcheniya-organicheskoj-produkcii/ (Дата обращения 22.05.2019).

\section{References}

1. Ezhegodnyj konsolidirovannyj otchet IFOAM-2017 (Annual consolidated report of the IFOAM-2017) URL: https://ifoam bio. (Accessed: 22.05.2019). (In Russian).

2. V Evrazijskom ekonomicheskom soyuze vyrabatyvayut pravila obrashcheniya organicheskoj produkcii (The Eurasian Economic Union develops rules for the circulation of organic products) URL: https://soz.bio/v-evrazijskom-ekonomicheskomsoyuze-vyrabatyvayut-pravila-obrashcheniya-organicheskoj-produkcii/. (In Russian).

\section{Информация об авторах}

Навасардова Элеонора Сергеевна - доктор юридических наук, профессор, заведующая кафедрой экологического, земельного и трудового права юридического института Северо-Кавказского федерального университета (Ставрополь)/ navasardova@yandex.ru

Захарьин Андрей - кандидат философских наук, доцент кафедры экологического, земельного и трудового права юридического института Северо-Кавказского федерального университета (Ставрополь).

\section{Information about the authors}

Navasardova Eleonora - Doctor of Law, Professor, Head of Chair of Environmental, Land and Labour Law, Institute of Law, North-Caucasus Federal University (Stavropol) / navasardova@yandex.ru

Zakharin Andrey - PhD in Philosophy, Associate Professor, Chair of Environmental, Land and Labour Law, Institute of Law, North-Caucasus Federal University (Stavropol) / colobichin@yandex.ru 